\title{
Tower and Path-Dependent Voltage Effects on the Measurement of Grounding Impedance for Lightning Studies
}

\author{
Antonio Šunjerga, Daniel S. Gazzana, Dragan Poljak ${ }^{\circledR}$, Senior Member, IEEE, Hamidreza Karami ${ }^{\circledR}$, \\ Keyhan Sheshyekani ${ }^{\circledR}$, Senior Member, IEEE, Marcos Rubinstein, Fellow, IEEE, \\ and Farhad Rachidi ${ }^{(-)}$, Fellow, IEEE
}

\begin{abstract}
We present an analysis aimed at evaluating the effect of the presence of the tower on the measurement of the grounding impedance. The Numerical Electromagnetics Code NEC-4 is used for the full-wave modeling of the structure including the tower and its footing grounding system, as well as the experimental setup used for the measurement of the grounding impedance. First, the effect of possible path-dependence in the evaluation of the integral of the electric field is investigated. It is shown that, up to a frequency of about $100 \mathrm{kHz}$ or so, the voltage, and consequently the evaluated impedance are independent of the path of integration. At higher frequencies, differences appear, which might be significant especially for poor conducting ground. The effect of the distance to the reference remote earth on the evaluated voltage is also analyzed and it is shown that a distance of $100 \mathrm{~m}$ to the remote earth is appropriate to evaluate the grounding impedance potential rise. The simulation results show that at low frequencies (up to about $200 \mathrm{kHz}$ or so for the considered 140-m tall tower), the effect of the presence of the tower can be disregarded. At higher frequencies, the evaluated impedance is affected by the presence of the tower. The poorer the ground conductivity, the more significant the effect of the presence of the tower on the evaluated impedance. Two injected current waveforms, representative of typical first and subsequent return strokes, are considered for the time-domain analysis. The effect of the presence of the tower can be significant for subsequent return stroke excitation, which has a wider frequency spectrum compared to first return strokes. It is shown that in the early-time region, part of the injected current flows into the tower. For a ground conductivity of $0.001 \mathrm{~S} / \mathrm{m}$, the tower peak current
\end{abstract}

Manuscript received February 28, 2018; accepted March 19, 2018. (Corresponding author: Farhad Rachidi.)

A. Sunjerga and F. Rachidi are with the Swiss Federal Institute of Technology, Lausanne 1015, Switzerland (e-mail: antonio.sunjerga@epfl.ch; farhad.rachidi@epfl.ch).

D. S. Gazzana is with the Swiss Federal Institute of Technology, Lausanne 1015, Switzerland, and also with the Department of Automation and Energy, Federal University of Rio Grande do Sul University, Porto Alegre 90035-190, Brazil (e-mail: daniel.dasilvagazzana@epfl.ch).

D. Poljak is with the Faculty of Electrical Engineering, Mechanical Engineering and Naval Architecture, University of Split, Split 21000, Croatia (e-mail: dpoljak@fesb.hr).

H. Karami is with the Department of Electrical Engineering, Bu-Ali Sina University, Hamedan 6517838695, Iran (e-mail: hamidr.karami@basu.ac.ir).

K. Sheshyekani is with the Ecole Polytechnique de Montreal, Montreal, QC H3T 1J4, Canada (e-mail: keyhan.sheshyekani@polymtl.ca).

M. Rubinstein is with the University of Applied Sciences Western Switzerland, Yverdon-les-Bains 1400, Switzerland (e-mail: marcos. rubinstein@heig-vd.ch).

Color versions of one or more of the figures in this paper are available online at http://ieeexplore.ieee.org.

Digital Object Identifier 10.1109/TEMC.2018.2819693 increases to about $10 \%$ of the exciting current, for the case of a subsequent strokes. It is also shown that the presence of the tower would cause a decrease in the peak potential rise leading therefore to an underestimation of the so-called impulsive grounding impedance.

Index Terms-Grounding impedance, lightning, path-dependent voltage, wind turbine.

\section{INTRODUCTION}

W IND is one of the most important sources of renewable energy. The amount of energy produced by wind turbines is constantly growing. The growth is provided by installing new units, often with greater power capacity obtained by making bigger wind turbines. Due to their height and sharp edges, wind turbines are very vulnerable to lightning [1], [2]. Lightning discharges can cause severe damage to the structure itself and to related electric and electronic systems. Not only do tall structures attract downward discharges but also, more importantly, they initiate upward discharges [3]. The number of upward flashes initiated from a tall structure depends on a number of factors including the structure height and the local terrain elevation [4].

Therefore, the appropriate design of the lightning protection system (LPS) of wind turbines is very important. The performance the LPS depends strongly on the quality of the grounding system, which is quantified through the evaluation of its grounding impedance [5], [6] over the frequency range of interest, namely, from dc to a few $\mathrm{MHz}$ [7]. Nevertheless, the grounding system requires constant maintenance and inspection. During these inspections, the grounding impedance is measured in presence of the wind turbine and the question arises as to extent to which the measured impedance is affected by the presence of the turbine [8], [9].

The aim of this paper is to present an analysis aimed at evaluating the effect of the presence of the tower on the measurement of the grounding impedance. In the analysis, the effect of the experimental setup used for the measurement of the grounding impedance is taken into account. The study is based on fullwave numerical simulations carried out using the Numerical Electromagnetics Code NEC-4, which is based on the method of moments (MOM) solution to Maxwell's equations [10]. 


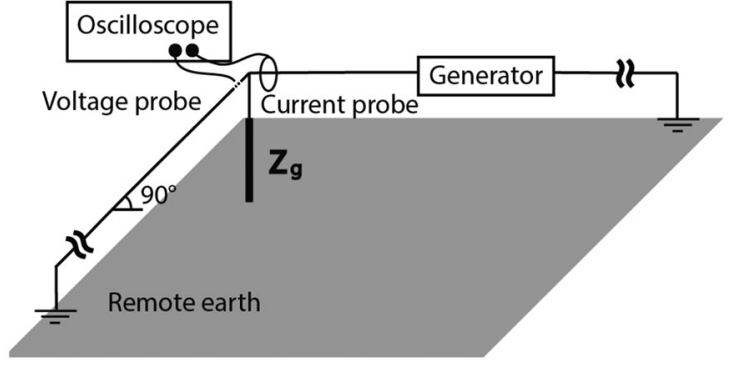

(a)

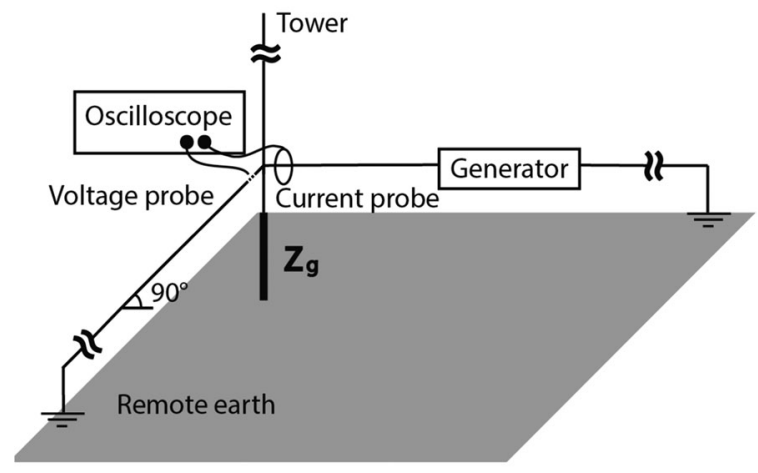

(b)

Fig. 1. (a) Measurement circuit. (b) Measurement circuit in presence of the tower.

\section{Geometry of the Problem}

\section{A. Grounding Impedance Measurement Circuit}

The circuit for the measurement of the grounding impedance, for the fall-of-potential method as suggested in [11], consists of a generator grounded at a remote point and injecting a continuous wave or a transient current to the grounding of the system under test [see Fig. 1(a)]. The voltage caused by the current injection is measured using an insulated probe wire extended from the grounding system to a remote ground electrode. It is recommended [12] that the potential probe wire be much longer than the dimensions of the grounding system and with an angle of $90^{\circ}$ with respect to the current injection path in order to reduce mutual coupling effects. The grounding impedance is obtained by the ratio of the measured voltage to the injected current. In the case of an impulse current injection, further signal processing is needed to infer the Fourier transforms of the time-domain waveforms.

Fig. 1(b) shows the same measurement setup in presence of a tower (wind turbine). In this case, part of the high-frequency current injected by the source can flow into the tower.

\section{B. Considered Configuration for the Analysis}

The considered configuration for the analysis, which is aimed at reproducing the experimental setup for the measurement of the impedance of a grounding system, is schematically shown in Fig. 2. The tower is represented by a vertical cylinder of radius $a=1.25 \mathrm{~cm}$ and height $H=140 \mathrm{~m}$. The grounding of the tower is assumed to be a simple vertical rod of length $L$. However, the study can be easily extended to more complex

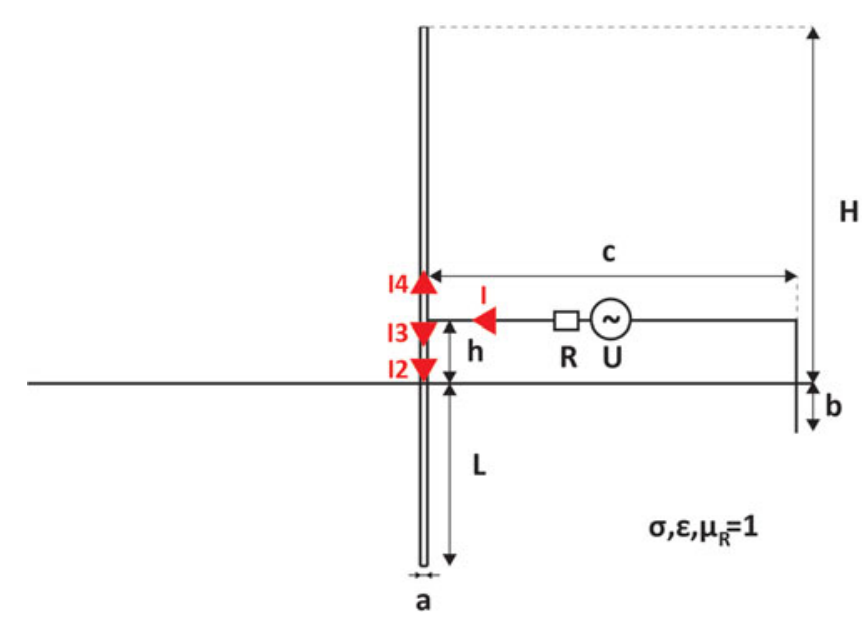

Fig. 2. Geometry of configuration used in numerical simulations. The injected current $I$ is evaluated right before the junction to the structure. $I_{2}$ is the current injected into the ground, $I_{3}$ is the part of $I$ that flows down, and $I_{4}$ is the part of $I$ that flows up into the tower. Note that $I_{2}$ and $I_{3}$ are essentially identical up as long as $\mathrm{h}$ is electrically small.

TABLE I

GeOMETRICAL AND ELECTRICAL PARAMETERS (SEE Fig. 2 FOR THE DEFINITION OF A, B, C, U, R, H, AND H, AND FIG. 4 FOR THE DEFINITION OF E AND D)

\begin{tabular}{cccccccc}
\hline \hline $\mathrm{a}[\mathrm{cm}]$ & $\mathrm{h}[\mathrm{m}]$ & $\mathrm{b}=\mathrm{e}[\mathrm{m}]$ & $\mathrm{c}=\mathrm{d}[\mathrm{m}]$ & $\mathrm{U}[\mathrm{MV}]$ & $\mathrm{R}[\mathrm{M} \Omega]$ & $\varepsilon_{R}$ & $\mathrm{H}[\mathrm{m}]$ \\
\hline 1.25 & 0.8 & 0.5 & 100 & 1 & 1 & 10 & 140 \\
\hline \hline
\end{tabular}

grounding grids. Analytical expressions and circuit models can be found in the literature (see [13], [14] for towers or towerlike structures and [15], [16] for vertical grounding rods). Two different rod lengths of $3 \mathrm{~m}$ and $30 \mathrm{~m}$ will be considered in the analysis, as well as different ground electrical conductivities. Note that the frequency dependence of the electrical parameters of the ground (see, e.g., [17]) was not considered in this study. The considered height of the tower corresponds to a current typical wind turbine, such as the ones belonging to the Mont Crosin wind turbine park in Switzerland and reported in [8]. The geometrical and electrical parameters of the considered configuration are summarized in Table I. The generator for the current injection is modeled by a voltage source in series with high impedance $(1 \mathrm{M} \Omega)$.

\section{Computational Model}

\section{A. Frequency Domain}

The calculations are carried out using the NEC-4 code, which is based on the thin wire approximation and the numerical solution of the Pocklington's integro-differential equation [18] by means of the MoM [10].

The impedance of the input port at the point of the generator wire and tower junction in the frequency domain can be calculated as

$$
Z=\frac{V_{R}(f)}{I(f)}
$$


TABLE II

HEIDLER'S FUNCTION PARAMETERS FOR THE REPRESENTATION OF TYPICAL FIRST AND SUBSEQUENT RETURN STROKES (FROM [24])

\begin{tabular}{lllllllll}
\hline \hline & $\mathrm{l}_{01}(\mathrm{kA})$ & $\mathrm{T}_{11}(\mu \mathrm{s})$ & $\mathrm{T}_{21}(\mu \mathrm{s})$ & $\mathrm{n}_{1}$ & $\mathrm{I}_{02}(\mathrm{kA})$ & $\mathrm{T}_{12}(\mu \mathrm{s})$ & $\mathrm{T}_{22}(\mu \mathrm{s})$ & $\mathrm{n}_{2}$ \\
\hline First Stroke & 28 & 1.8 & 95 & 2 & - & - & - & - \\
$\begin{array}{l}\text { Subsequent } \\
\text { strokes }\end{array}$ & 10.7 & 0.25 & 2.5 & 2 & 6.5 & 2 & 230 & 2 \\
\hline \hline
\end{tabular}

where $I$ is the current injected by the generator evaluated just before the junction to the tower, and $V_{R}$ is the potential rise (voltage drop) of the grounding with respect to the remote earth, which can be evaluated as a line integral of the electric field

$$
V_{R}(f)=\int_{\substack{x, y=0 \\ z=h}}^{\text {remote earth }} \vec{E}(\vec{r}, f) \cdot \overrightarrow{d s}
$$

where the electric field is evaluated using NEC-4. NEC-4 is mainly designed for high-frequency antenna analysis and it breaks down at low frequencies (see, e.g., [19]). To overcome this problem, the low-frequency impedance calculation is based on the transmission line theory using the following analytical expressions to calculate the per-unit-length parameters for a vertical grounding rod, [20]-[22]:

$$
\begin{aligned}
R^{\prime} & =\frac{1}{G^{\prime}}=\frac{\rho}{2 \pi}\left(\ln \left(\frac{4 L}{a}\right)-1\right) \\
C^{\prime} & =2 \pi \varepsilon\left(\ln \left(\frac{4 L}{a}\right)-1\right) \\
L^{\prime} & =\frac{\mu_{0}}{2 \pi}\left(\ln \left(\frac{4 L}{a}\right)-1\right) .
\end{aligned}
$$

The low-frequency limit (typically about $10 \mathrm{kHz}$ ) is chosen in such a way that there is minimum discontinuity between the NEC-4 and transmission line (TL) theory results. The impedance is calculated at discrete frequencies with adaptive resolution (higher resolution was considered in areas of resonant frequencies).

\section{B. Time Domain}

In order to consider the influence of the injected current waveform on the impact of the presence of the tower, two waveforms corresponding to typical first and subsequent return strokes will be considered. The waveforms are represented using Heidler's function, defined as [23]

$$
I(t)=\frac{I_{0}}{\eta} \frac{\left(\frac{t}{\tau_{1}}\right)^{n}}{1+\left(\frac{t}{\tau_{1}}\right)^{n}} e^{-\frac{t}{\tau_{2}}}
$$

where $\eta$ can be calculated as

$$
\eta=e^{\left(-\frac{\tau_{1}}{\tau_{2}}\left(n \frac{\tau_{2}}{\tau_{1}}\right)^{-n}\right)} .
$$

The parameters of the Heidler's functions for the two waveforms are the same used in [24] and they are given in Table II. Note that the sum of two Heidler's functions is used for the

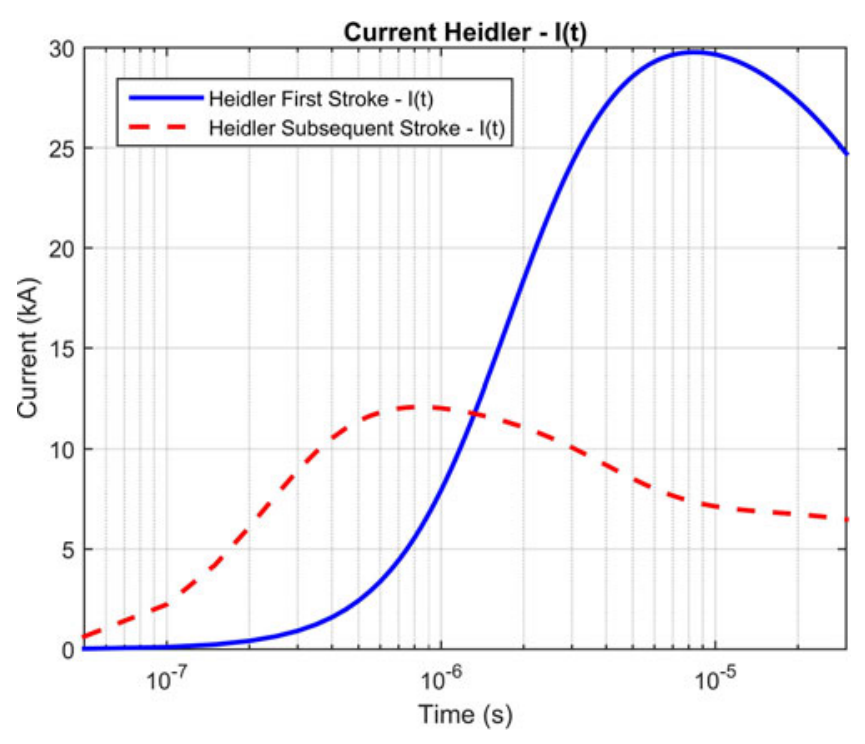

Fig. 3. Excitation current waveforms represented using Heidler's functions. First return stroke (solid blue); subsequent return strokes (dashed red).

representation of the subsequent stroke. The early-time behavior of the two waveforms is shown in Fig. 3.

The voltage of the source $U(t)$ is determined in order to specify the injected current $I(t)$ with either the first or the subsequent return stroke waveform defined by the Heidler's functions

$$
U(t)=\mathcal{F}^{-1}\left[Z_{t r}(f)\right] * I(t)
$$

in which $Z_{t r}(f)$ is the transfer function between the voltage source and the injected current, calculated by applying a Dirac excitation current ( $1 \mathrm{~A}$ at every frequency through the $1-\mathrm{MV}$ voltage source in series with 1-M $\Omega$ impedance). Inverse Fourier transforms are evaluated by way of the inverse FFT (IFFT) algorithm [25]. Simulated impedances are interpolated using the Spline algorithm [26], to have uniform sampling in the frequency domain, to make them adequate for the IFFT algorithm.

\section{Voltage Path DePendence}

Since we have a time-dependent magnetic flux, the electric field is not irrotational and, therefore, it is nonconservative [27]. As a result, the voltage (2) is path dependent [13]. Two different paths are considered for the electric field integration (see Fig. 4). The first one ( $S_{1}$ in the figure) corresponds to the setup used for grounding impedance measurements, while the second one (where the horizontal part is integrated $5 \mathrm{~cm}$ below the ground surface) has been used in theoretical analyzes (see, e.g., [17]). The distance $d$ to the remote earth is assumed to be $100 \mathrm{~m}$. The results are shown for conductivities $\sigma=0.01 \mathrm{~S} / \mathrm{m}$ in Fig. 5 and $\sigma=0.001 \mathrm{~S} / \mathrm{m}$ in Fig. 6. Other adopted parameters are specified in Table I.

As expected, at low frequencies (up to a frequency of about $100 \mathrm{kHz}$ ), the voltage, and consequently the evaluated impedance are independent of the path of integration. At higher frequencies, differences appear, which might be significant, 


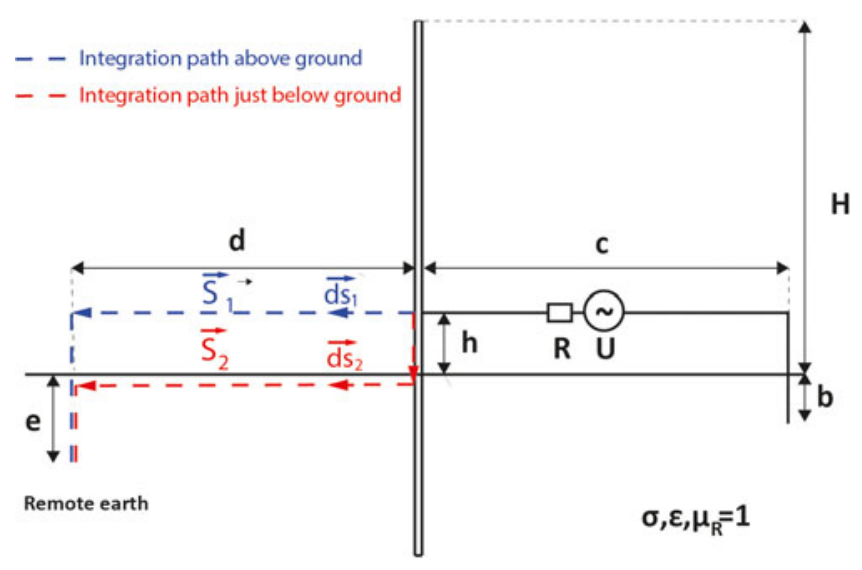

Fig. 4. Different integration paths.

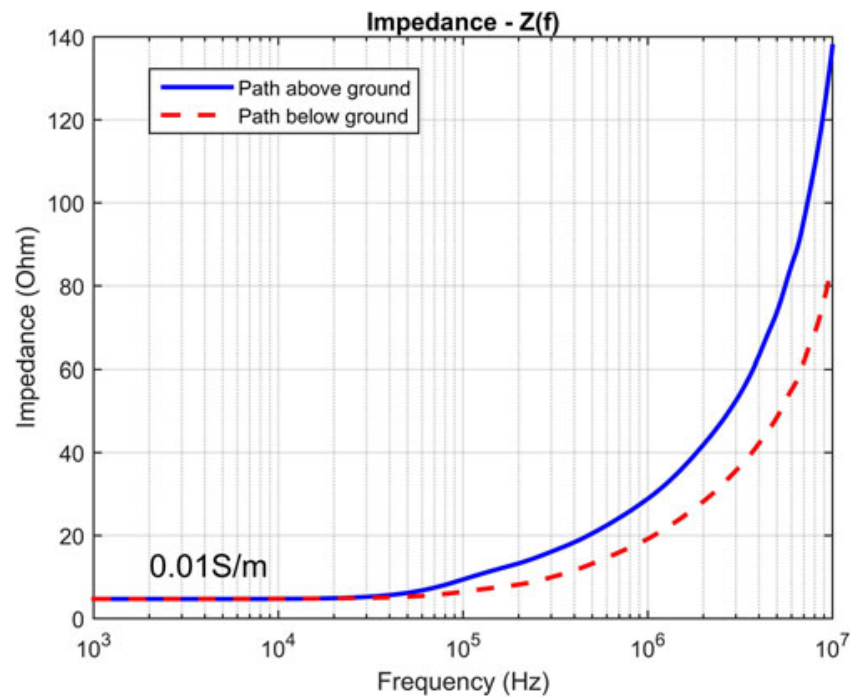

Fig. 5. Magnitude of the grounding impedance in absence of the tower. $\sigma=$ $0.01 \mathrm{~S} / \mathrm{m} L=30 \mathrm{~m}$. Path above ground (solid blue), and path below ground (dashed red).

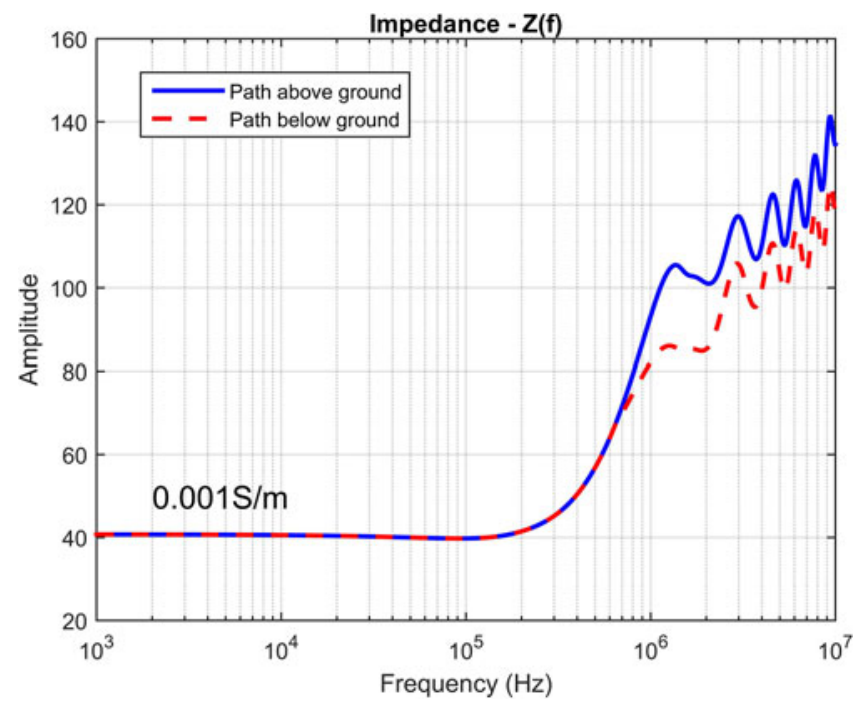

Fig. 6. Magnitude of the grounding impedance in absence of the tower. $\sigma=$ $0.001 \mathrm{~S} / \mathrm{m} L=30 \mathrm{~m}$. Path above ground (solid blue), and path below ground (dashed red).

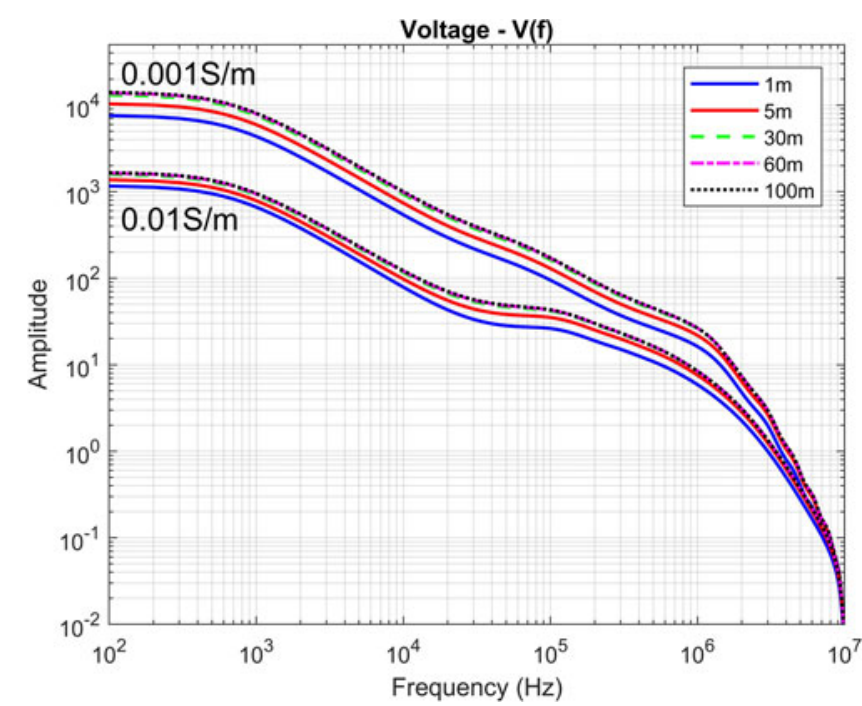

Fig. 7. Grounding potential rise for different remote earth distances. Ground conductivities: $\sigma=0.001 \mathrm{~S} / \mathrm{m}$ and $\sigma=0.01 \mathrm{~S} / \mathrm{m}, L=30 \mathrm{~m}$. Subsequent stroke excitation.

especially for a poorly conducting ground. Note that different approaches have been proposed to deal with the path-dependent voltage. For example, in [28], the voltage is expressed in terms of an integral involving the current derivative and the corresponding Green's function. Another approach, proposed in [16], uses a path-independent method to evaluate the grounding impedance.

In the analyses that follow, the voltage is evaluated integrating along the path above the ground since it better matches the setup used for the measurement of impedance of grounding systems.

Different remote earth distances were considered to confirm the convergence of the results. Results for the voltage are presented in Fig. 7 and for a subsequent stroke excitation. It can be seen from Fig. 7 that beyond a distance of $30 \mathrm{~m}$, the results converge at all frequencies. In what follows, we will consider a distance to remote earth of $100 \mathrm{~m}$.

\section{TOWER EFFECTS: RESULTS AND ANALYSIS}

\section{A. Grounding Impedance}

Figs. 8 and 9 present the grounding impedance evaluated with and without the tower for a 3-m long grounding rod, and considering two different ground conductivities $(0.01 \mathrm{~S} / \mathrm{m}$ in Fig. 8 and $0.001 \mathrm{~S} / \mathrm{m}$ in Fig. 9). As expected, at low frequencies up to about $300 \mathrm{kHz}$ (for $\sigma=0.01 \mathrm{~S} / \mathrm{m}$ ) and $100 \mathrm{kHz}$ (for $\sigma=0.001 \mathrm{~S} / \mathrm{m}$ ), the tower does not affect the evaluated grounding impedance. At higher frequencies, the evaluated grounding impedance is clearly contaminated by the presence of the tower, with the appearance of resonances that correspond to the multiples of the quarter-wavelength frequency. For the case of poor ground conductivity, the resonant frequency of the grounding rod at about $8 \mathrm{MHz}$ is also clearly visible (see dashed line in Fig. 9). That resonant frequency corresponds to a wavelength equal to one-quarter of the rod's length.

Figs. 10 and 11 present similar results to Figs. 8 and 9, but considering a 30-m long grounding rod. Again, the effect of the 


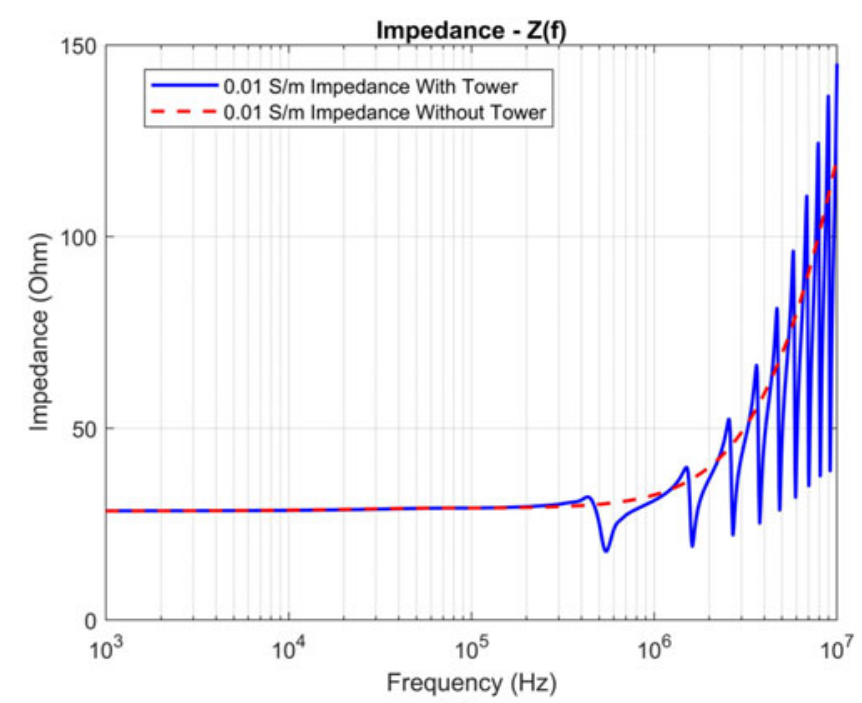

(a)

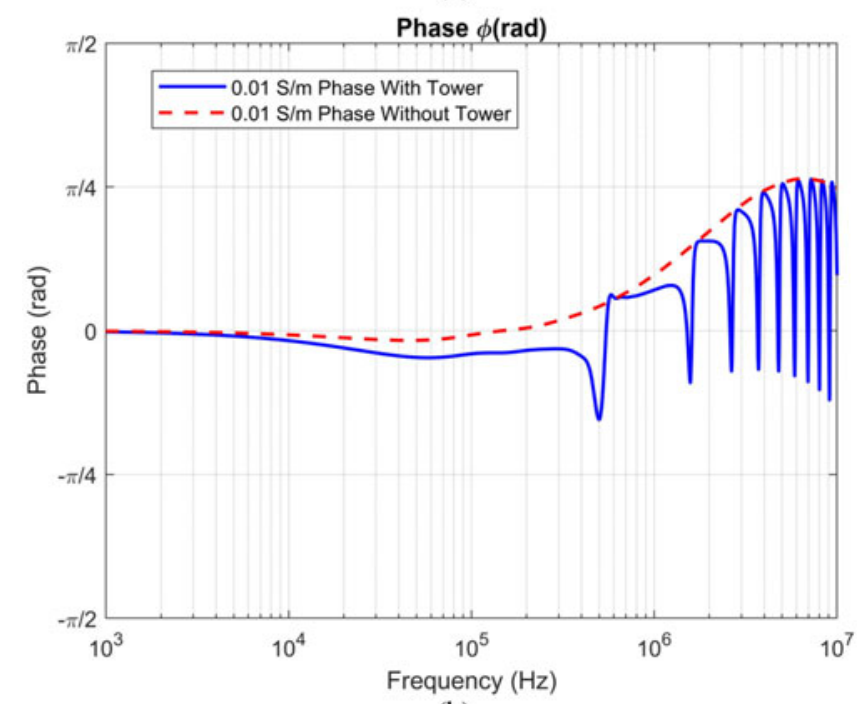

(b)

Fig. 8. (a) Magnitude. (b) Phase of the grounding impedance. $\sigma=0.01 \mathrm{~S} / \mathrm{m}$ $L=3 \mathrm{~m}$. With the tower (solid blue); without the tower (dashed red).

presence of the tower results in the appearance of resonance frequencies, which are clearly discernible in the evaluated grounding impedance. At low frequencies up to $200 \mathrm{kHz}$ or so, the effect of the presence of the tower can be disregarded. Note that the first resonant frequency depends on the tower height: for taller towers, it will occur at lower frequencies.

\section{B. Current Distribution}

Figs. 12 and 13 show, for the case of a subsequent stroke excitation, the magnitudes of the current delivered by the generator, the current injected into the grounding and the current into the tower as a function of frequency. Consistent with the results of the grounding impedance, it can be seen that at low frequencies, nearly all the current out of the generator is injected into the grounding, while practically no current circulates in the tower. At the tower resonant frequencies, its impedance has minimum value and, consequently, the tower current features local maxima. Comparing Figs. 12 and 13, it can be observed that as

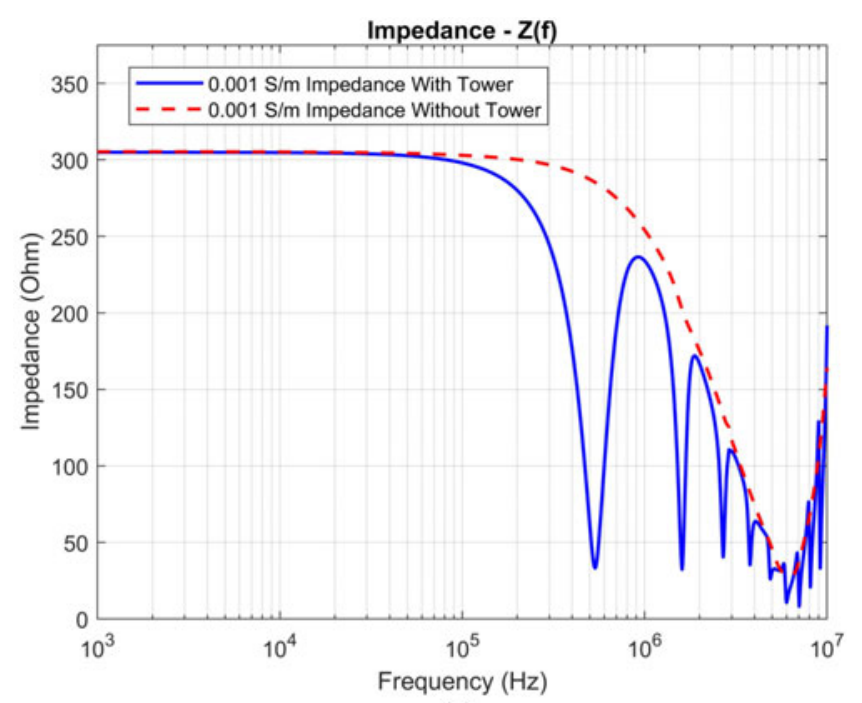

(a)

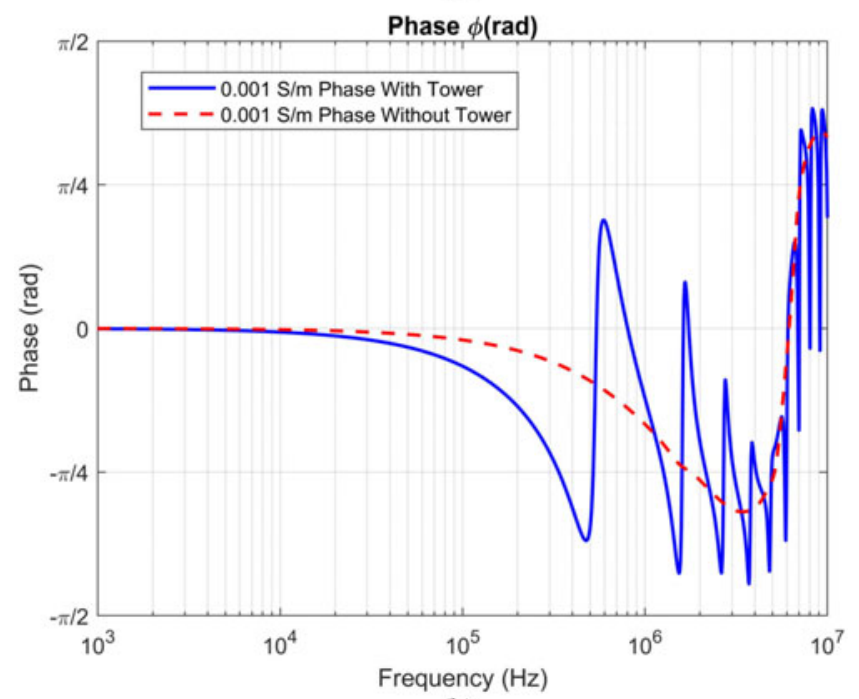

(b)

Fig. 9. (a) Magnitude. (b) Phase of the grounding impedance. $\sigma=0.001 \mathrm{~S} / \mathrm{m}$ $L=3 \mathrm{~m}$. With the tower (solid blue); without the tower (dashed red).

the soil conductivity decreases, more current flows through the tower.

\section{Time-Domain Voltage and Current Waveforms}

Fig. 14 presents the resulting time-domain potential rise when applying a current typical of first return strokes, and considering two different values for the ground conductivity, $0.01 \mathrm{~S} / \mathrm{m}$ and $0.001 \mathrm{~S} / \mathrm{m}$ with and without the tower. It can be seen that the presence of the tower does not significantly affect the voltage waveform and amplitude, for a first-stroke excitation.

Fig. 15 presents similar results associated with the injection of a current typical of subsequent return strokes. In this case, because of the current faster rise time, and thus, higher frequency content of its spectrum, the effect of the presence of the tower can be seen, especially for the poor ground conductivity. Indeed, for $\sigma=0.001 \mathrm{~S} / \mathrm{m}$ in the presence of the tower, the peak potential rise is underestimated by about $15 \%$. 


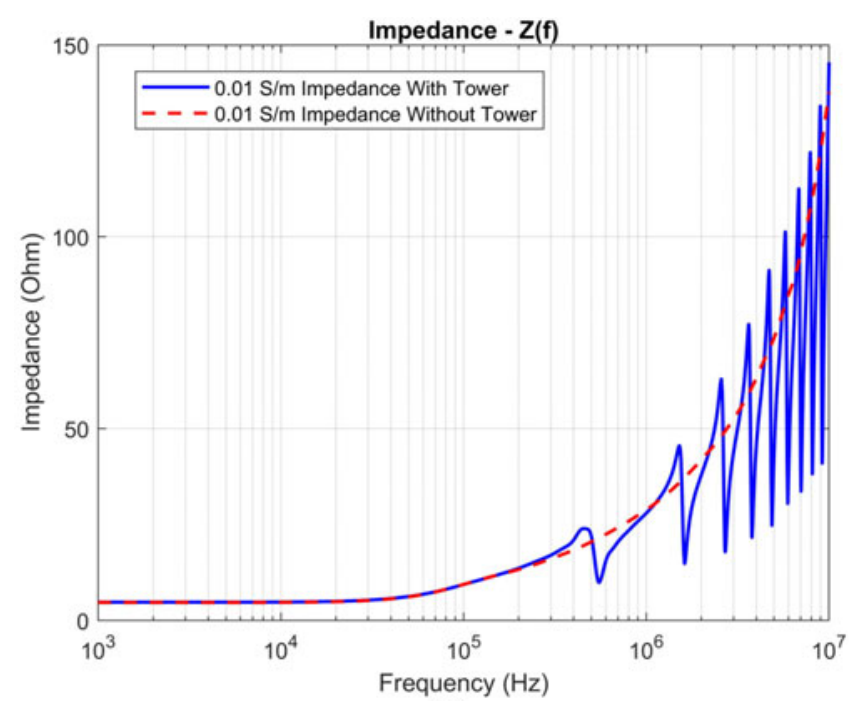

(a)

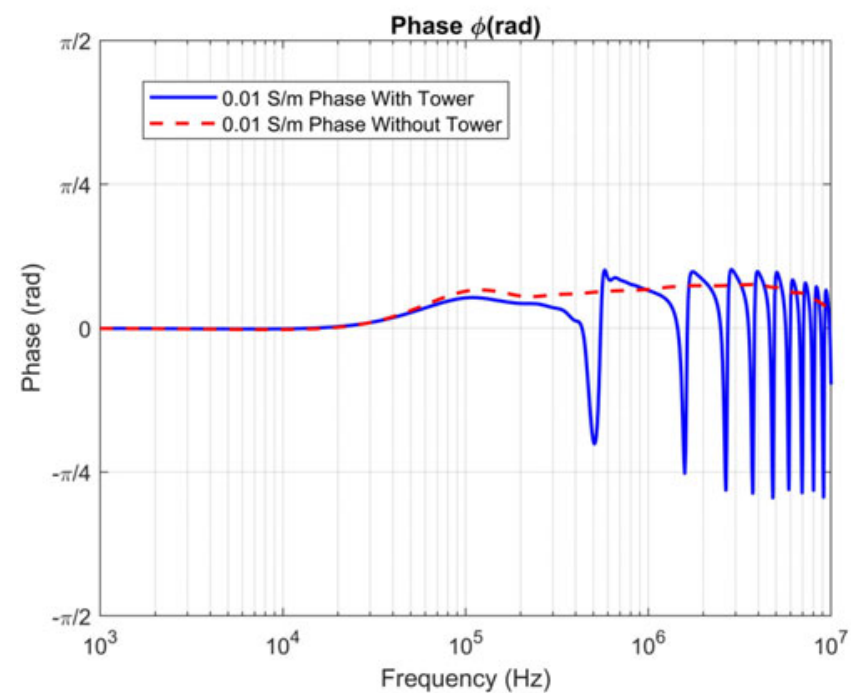

(b)

Fig. 10. (a) Magnitude. (b) Phase of the grounding impedance. $\sigma=0.01 \mathrm{~S} / \mathrm{m}$ $L=30 \mathrm{~m}$. With the tower (solid blue); without the tower (dashed red).

Figs. 16 and 17 represent the time-domain current waveforms for a subsequent return stroke excitation. It can be seen that in the early-time region, a fraction of the injected current flows into the tower ( $I_{4}$ in Figs. 16 and 17; see also Fig. 2). For a ground conductivity of $0.01 \mathrm{~S} / \mathrm{m}$, the peak of the tower current is about $4 \%$ of the exciting current peak. For a poorer ground $(\sigma=$ $0.001 \mathrm{~S} / \mathrm{m}$ ), the tower peak current increases to about $10 \%$ of the exciting current. The results for the first stroke are not present since, similar to the voltage, the tower effects are negligible.

Furthermore, it should be noted that the frequency spectrum of subsequent strokes is not high enough to distinguish the effects of the grounding rod reflections in the time-domain waveforms.

The influence of the tower height on the evaluated potential rise is shown in Fig. 18, in which the potential rise is presented considering three different tower heights $(100,140$, and 180 $\mathrm{m}$. The effect of the reflections from the tower top is clearly discernible in the waveforms. The first reflection is observed at a time corresponding to $2 \mathrm{H} / \mathrm{c}$, where $c$ is the speed of light. For

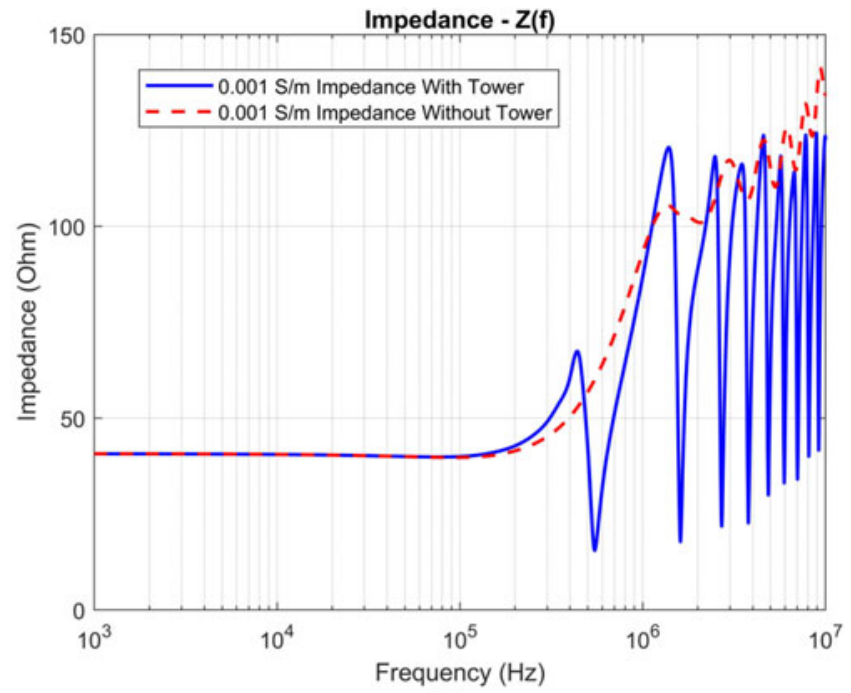

(a)

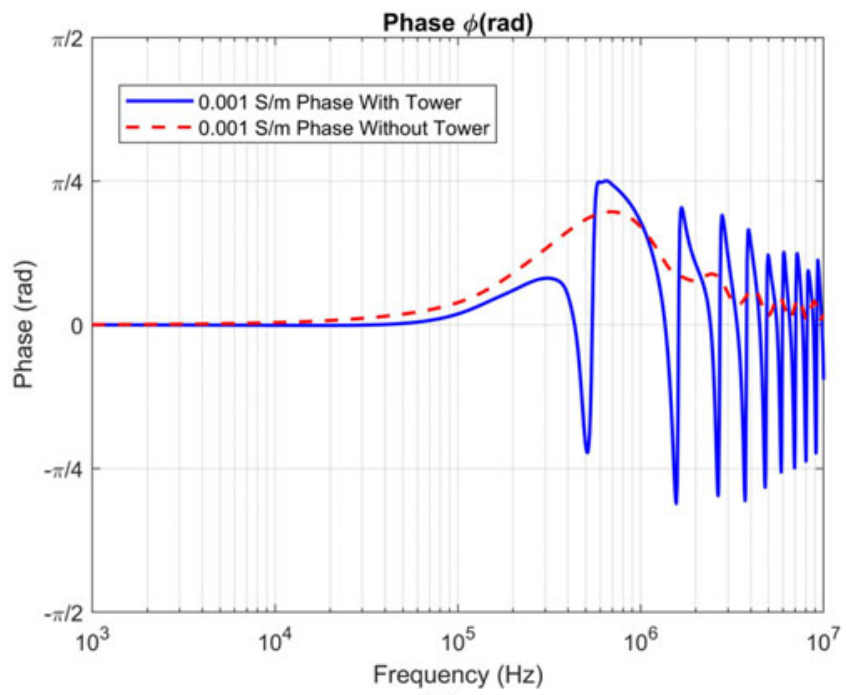

(b)

Fig. 11. (a) Magnitude. (b) Phase of the grounding impedance. $\sigma=$ $0.001 \mathrm{~S} / \mathrm{m} L=30 \mathrm{~m}$. With the tower (solid blue); without the tower (dashed red).

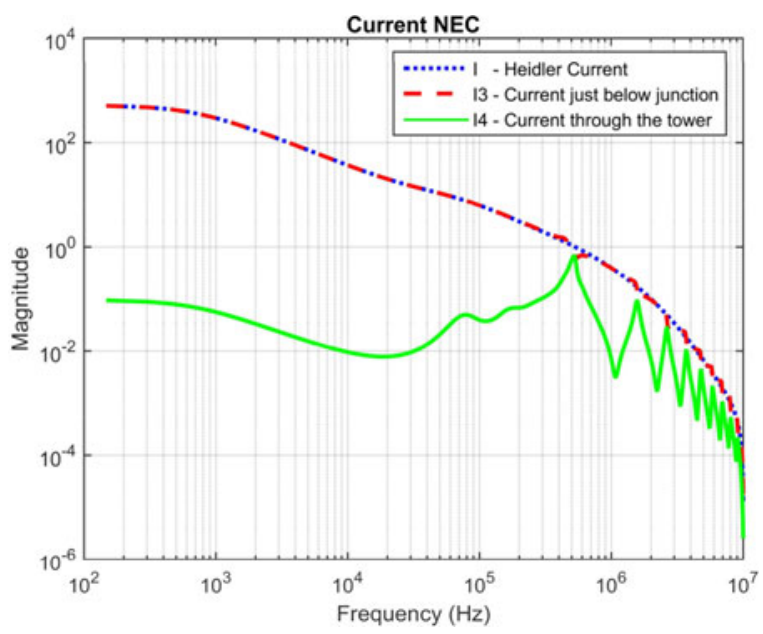

Fig. 12. Magnitudes of the current delivered by the generator $I$, the current injected into the grounding $I_{3}$, and the current into the tower $I_{4}$ as a function of frequency. Subsequent stroke excitation. $\sigma=0.01 \mathrm{~S} / \mathrm{m}, L=30 \mathrm{~m}$. 


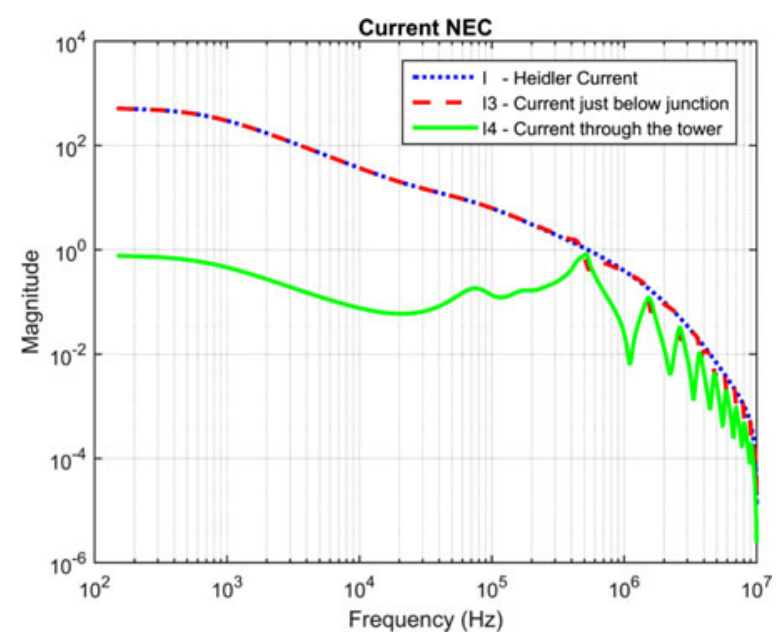

Fig. 13. Magnitudes of the current delivered by the generator $I$, the current injected into the grounding $I_{3}$, and the current into the tower $I_{4}$ as a function of frequency. Subsequent stroke excitation. $\sigma=0.001 \mathrm{~S} / \mathrm{m}, L=30 \mathrm{~m}$.

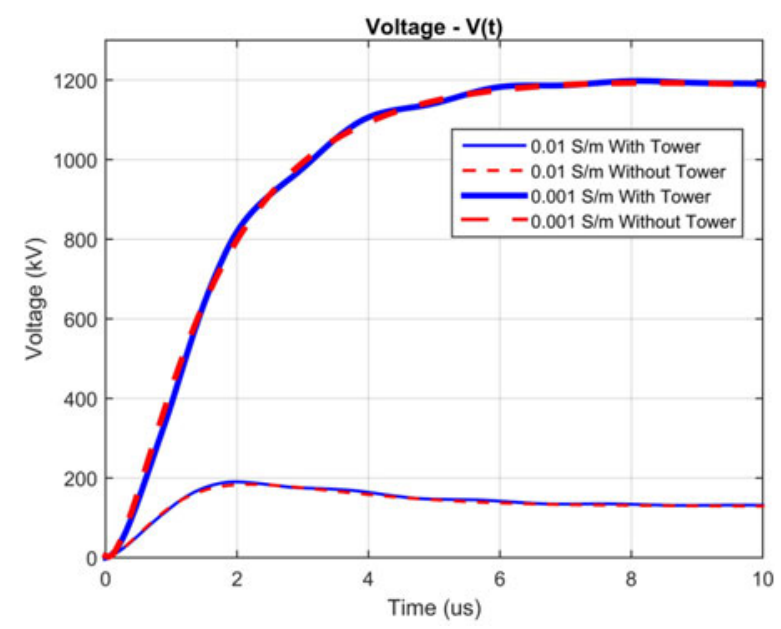

Fig. 14. Grounding potential rise for a first return stroke excitation. $L=$ $30 \mathrm{~m}$. With the tower (solid blue), and without the tower (dashed red). $\sigma=$ $0.01 \mathrm{~S} / \mathrm{m}$ and $\sigma=0.001 \mathrm{~S} / \mathrm{m}$ (bold).

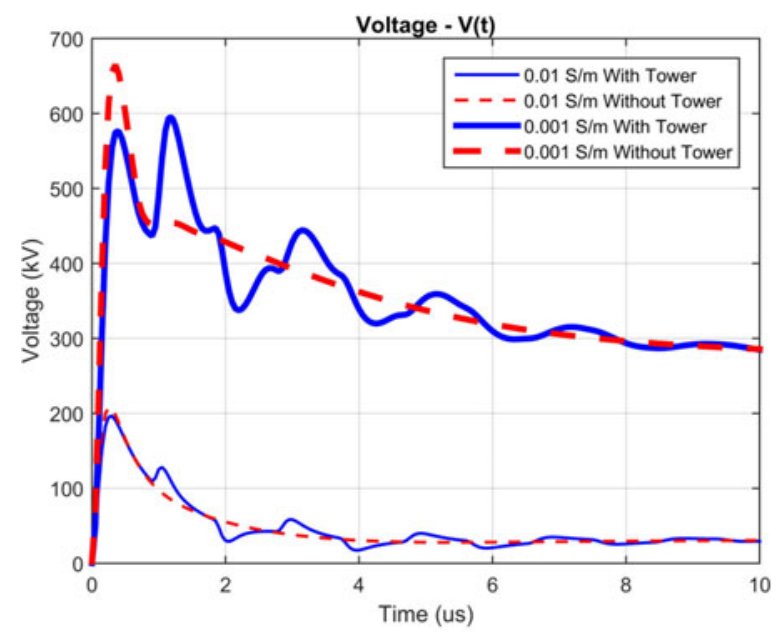

Fig. 15. Grounding potential rise for a subsequent return stroke excitation. $L=30 \mathrm{~m}$. With the tower (solid blue), and without the tower (dashed red). $\sigma=0.01 \mathrm{~S} / \mathrm{m}$ and $\sigma=0.001 \mathrm{~S} / \mathrm{m}$ (bold).

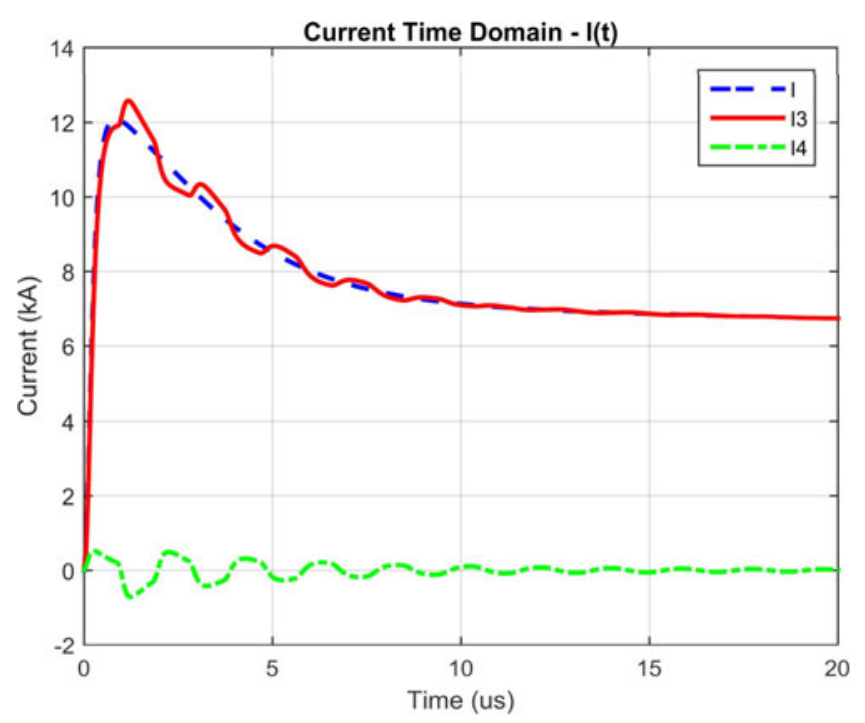

Fig. 16. Time-domain waveforms of the current delivered by the generator $I$ : the current $I_{3}$ flowing down toward the ground from the junction of the generator, the grounding rod and the tower, and the current $I_{4}$ that flows up into the tower at the same junction. Subsequent stroke excitation. $\sigma=0.01 \mathrm{~S} / \mathrm{m}$, $L=30 \mathrm{~m}$.

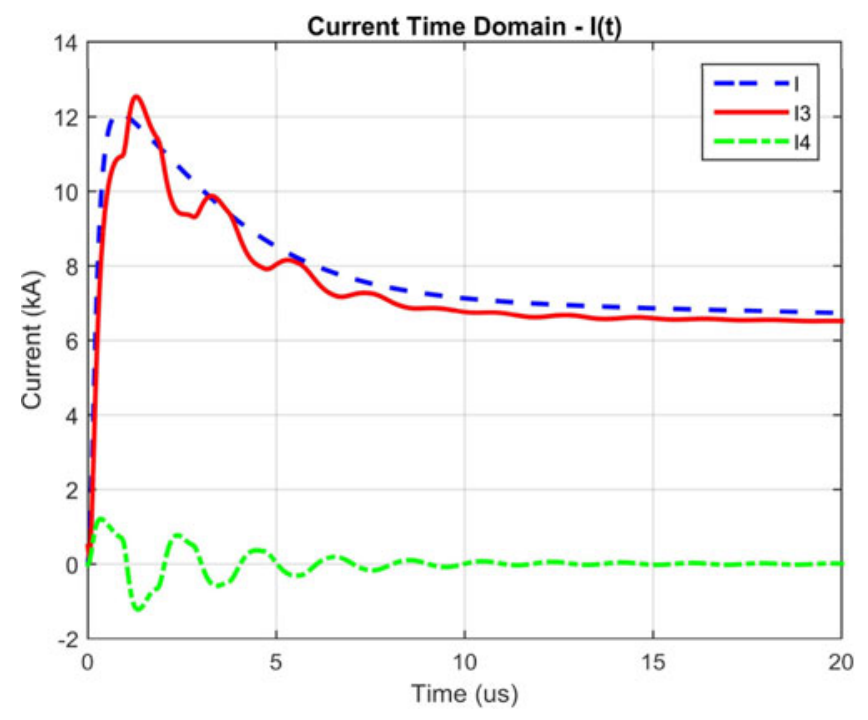

Fig. 17. Time-domain waveforms of the current delivered by the generator $I$ : the current $I_{3}$ flowing down toward the ground from the junction point of the generator, the grounding rod and the tower, and the current $I_{4}$ that flows up into the tower at the same junction. Subsequent stroke excitation. $\sigma=0.001 \mathrm{~S} / \mathrm{m}$, $L=30 \mathrm{~m}$.

excitations with rise times faster than $2 H / c$, the resulting peak potential rise will be 1) smaller than that corresponding to the case where no tower is present, and 2) independent of the tower height.

The transient behavior of grounding systems is often characterized by the so-called impulsive grounding impedance, defined as the ratio of the peak potential rise to the peak current [29]. For the same injected current, the presence of the tower would cause a decrease in the peak potential rise (see Figs. 15 and 18), leading, therefore, to an underestimation of the impulsive 


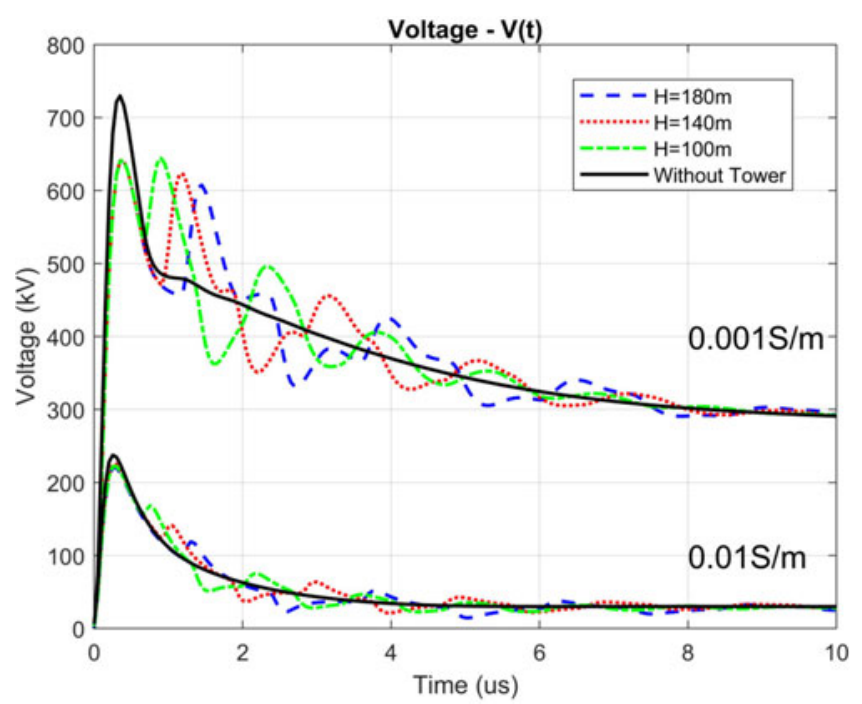

Fig. 18. Influence of the tower height on the grounding potential rise. $\sigma=$ $0.001 \mathrm{~S} / \mathrm{m}$ and $\sigma=0.01 \mathrm{~S} / \mathrm{m}, L=30 \mathrm{~m}$. Subsequent return stroke excitation.

grounding impedance. For example, for a ground conductivity of $0.001 \mathrm{~S} / \mathrm{m}$, the estimated value for the impulsive grounding impedance in the case of a subsequent return stroke excitation would be $48 \Omega$ in presence of a 140-m tall tower, instead of a value of $55 \Omega$ for the grounding system alone.

\section{CONCLUSION}

We presented an analysis aimed at evaluating the effect of the presence of the tower on the measurement of the grounding impedance. The study was carried out using full-wave numerical simulations obtained using the Numerical Electromagnetics Code NEC-4, which is based on the MOM. The effect of the experimental setup used for the measurement of the grounding impedance was taken into account in the analysis.

We investigated first the effect of possible path-dependence in the evaluation of the integral of the electric field. It was shown that, up to a frequency of about $100 \mathrm{kHz}$ or so, the voltage and consequently the evaluated impedance are independent of the path of integration. At higher frequencies, differences appear, which might be significant especially for poorly conducting grounds.

We also analyzed the effect of the distance to the reference remote earth on the evaluated voltage and it was shown that a distance of $100 \mathrm{~m}$ to the remote earth is appropriate to evaluate the grounding impedance potential rise.

The simulation results have shown that at low frequencies (up to about $200 \mathrm{kHz}$ or so for the considered 140-m tall tower), the effect of the presence of the tower can be disregarded. At higher frequencies, the evaluated impedance is affected by the presence of the tower. The poorer the ground conductivity, the more significant the effect of the presence of the tower on the evaluated impedance.

Two injected current waveforms, representative of typical first and subsequent return strokes, were considered for the time-domain analysis. The effect of the presence of the tower can be significant for subsequent return stroke excitation, which has a wider frequency spectrum compared to first return strokes. It was shown that in the early-time region, part of the injected current flows into the tower. For a ground conductivity of $0.01 \mathrm{~S} / \mathrm{m}$, the peak of the tower current is about $4 \%$ of the exciting current peak. For a poorer ground $(\sigma=0.001 \mathrm{~S} / \mathrm{m})$, the tower peak current increases to about $10 \%$ of the exciting current, for a subsequent return strokes.

It was also shown that the presence of the tower would cause a decrease in the peak potential rise, leading, therefore, to an underestimation of the impulsive grounding impedance.

\section{ACKNOWLEDGMENT}

The authors would like to express their gratitude to Prof. R. Moini for his important comments and suggestions on the manuscript.

\section{REFERENCES}

[1] D. Poljak and D. Čavka, "Electromagnetic compatibility aspects of wind turbine analysis and design," Properties and Characterization of Modern Materials. Berlin, Germany: Springer-Verlag, Jul. 2016.

[2] F. Rachidi et al., "A review of current issues in lightning protection of new-generation wind-turbine blades," IEEE Trans. Ind. Electron., vol. 55, no. 6, pp. 2489-2496, Jun. 2008.

[3] F. Rachidi, M. Rubinstein, and A. Smorgonskiy, Lightning Protection of Large Wind-Turbine Blades, in Wind Energy Conversion Systems. Berlin, Germany: Springer-Verlag, 2012, pp. 227-242.

[4] A. Smorgonskiy, F. Rachidi, M. Rubinstein, G. Diendorfer, and W. Schulz, "On the proportion of upward flashes to lightning research towers," Atmos. Res., vol. 129-130, pp. 110-116, 2013.

[5] K. Yamamoto, S. Yanagawa, and T. Ueda, "Verifications of transient grounding impedance measurements of a wind turbine generator system using the FDTD method" in Proc. Int. Symp. Lightning Protect., Fortaleza, Brazil, Oct. 3-7, 2011.

[6] K. Yamamoto, S. Yanagawa, K. Yamabuki, S. Sekioka, and S. Yokoyama, "Analytical surveys of transient and frequency dependent grounding characteristics of a wind turbine generator system on the basis of field tests," IEEE Trans. Power Del., vol. 25, no. 4, pp. 3034-3043, Oct. 2010.

[7] CIGRE Working Group C4.407 (Convener: V.A. Rakov), "Lightning parameters for engineering applications," CIGRE, Paris, France, Tech. Brochure 549, 2014.

[8] A. Smorgonskiy, N. Mora, F. Rachidi, M. Rubinstein, K. Sheshyekani, and N. Korovkin, "Measurements of transient grounding impedance of a wind turbine at mont-crosin wind park," in Proc. Asia Pac. Int. Symp. Electromagn. Compat., Taipei, Taiwan, May 26-29, 2015, pp. 424-427.

[9] A. Smorgonskiy, D. Gazzana, N. Mora, M. Rubinstein, and F. Rachidi, "On the Measurement of the grounding impedance of tall wind turbines," in Proc. 12th Int. Conf. Power Syst. Transients, Seoul, South Korea, Jun. 26-29, 2017.

[10] G. J. Burke, "Numerical electromagnetics code (NEC-4)—Method of moments, Part II: Program description-Theory," Lawrence Livermore National Laboratory, Livermore, CA, USA, YCRL-MA-109338 PT. II. 1992.

[11] IEEE Guide for Measuring Earth Resistivity, Ground Impedance, and Earth Surface Potentials of A Grounding System, IEEE Std 81-2012 (Revision of IEEE Std 81-1983), Dec. 28, 2012.

[12] IEEE Guide for Measurement of Impedance and Safety Characteristics of Large, Extended or Interconnected Grounding Systems, IEEE Std 81.2-1991, IEEE, Jun. 25, 1992.

[13] L. Grcev and F. Rachidi, "On tower impedances for transient analysis," IEEE Trans. Power Del., vol. 19, no. 3, pp. 1238-1244, Jul. 2004.

[14] A. Šunjerga, F. Rachidi, and D. Poljak, "On wind turbine impedance analysis via different approaches" in Proc. 25th Int. Conf. Softw., Telecommun. Comput. Netw., Sep. 2017.

[15] L. Grcev and M. Popov, "On high-frequency circuit equivalents of a vertical ground rod," vol. 20, no. 2, pp. 1598-1603, Apr. 2005.

[16] B. Honarbakhsh, H. Karami, and K. Sheshyekani, "Direct characterization of grounding system wide-band input impedance," IEEE Trans. Electromagn. Compat., vol. 60, no. 1, pp. 292-293, Feb. 2018. 
[17] D. Cavka, N. Mora, and F. Rachidi, "A comparison of frequency dependent soil models: Application to the analysis of grounding systems," IEEE Trans. Electromagn. Compat., vol. 56, no. 1, pp. 177-187, Feb. 2014.

[18] D. Poljak, Advanced Modeling in Computational Electromagnetic Compatibility, Wiley, 2007, doi: 10.1002/0470116889.

[19] T. J. Cui and W. C. Chew "Accurate analysis of wire structures from verylow frequency to microwave frequency," IEEE Trans. Antennas Propag., vol. 50, no. 3, pp. 301-307, Mar. 2002.

[20] E. D. Sunde, Earth Conduction Effects in Transmission Systems. New York, NY, USA: Van Nostrand, 1949.

[21] S. Bourg, B. Sacepe, and T. Debu, "Deep earth electrodes in highly resistive ground: Frequency behavior," in Proc. IEEE Int. Symp. Electromagn. Compat., 1995, pp. 584-589.

[22] L. P. Kalantarov and L. A. Ceitlin, Inductance Calculation (in Russian). Leningrad, Russia: Energoatomizdat, 1986.

[23] F. Heidler, "Analytische Blitzstromfunktion zur LEMP- Berechnung," in Proc. 18th Int. Conf. Lightning Protect., Munich, Germany, Sep. 16-20, 1985, Paper 1.9, pp. 63-66.

[24] F. Rachidi et al., "Current and electromagnetic field associated with lightning-return strokes to tall towers," IEEE Trans. Electromagn. Compat., vol. 43, no. 3, 2001.

[25] M. Frigo, and S. G. Johnson, "FFTW: An Adaptive Software Architecture for the FFT," in Proc. Int. Conf. Acoustics, Speech, Signal Process., vol. 3, 1998, pp. 1381-1384.

[26] C. R. de Boor, A Practical Guide to Splines. New York, NY, USA: Springer-Verlag: 1978.

[27] J. D. Jackson, Classical Electrodynamics, 3rd ed. New York, NY, USA: Wiley 1999.

[28] D. Poljak, F. Rachidi, and S. V. Tkachenko "Generalized form of telegrapher's equations for the electromagnetic field coupling to finite-lengthlines above a lossy ground," IEEE Trans. Electromagn. Compat., vol. 49, no. 3, pp. 689-697, Aug. 2007.

[29] S. Visacro and G. Rosado, "Response of Grounding Electrodes to Impulsive Currents: An Experimental Evaluation," IEEE Trans. Electromagn. Compat., vol. 51, no. 1, pp. 161-164, Feb. 2009.

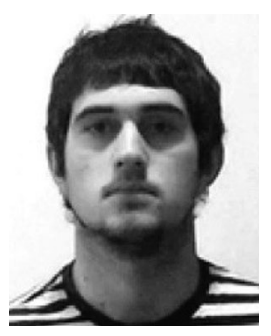

Antonio Šunjerga received the B.Sc. degree in physics and M.Sc. degree in communication and information technology both from the University of Split, Split, Croatia, both in 2017. He is currently working toward the Ph.D. degree in electrical engineering at the Electromagnetic Compatibility Laboratory, Swiss Federal Institute of Technology of Lausanne, Lausanne, Switzerland.

His research interests include lightning and electromagnetic compatibility

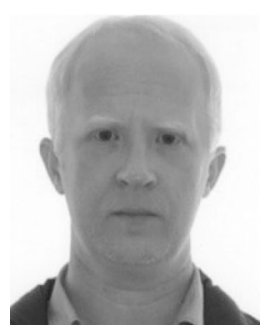

Daniel S. Gazzana was born in Veranópolis, Rio Grande do Sul, Brazil, December 6, 1977. He received the B.E. degree in mechatronics, the M.Sc. degree in electrical engineering, and the Ph.D. degree in electrical engineering all from the Federal University of Rio Grande do Sul, Porto Alegre, Brazil, in 2002, 2004, and 2012, respectively.

He is currently a Researcher and an Assistant Professor with the Department of Electrical Engineering, UFRGS. His main research fields are grounding systems, lightning, power systems, and numerical

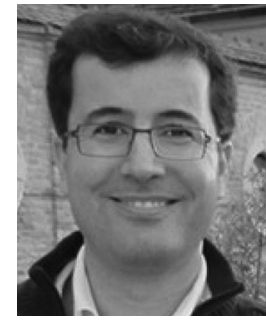

Keyhan Sheshyekani (M'10-SM'13) received the B.S. degree in electrical engineering from Tehran University, Tehran, Iran, in 2001, and the M.S. and $\mathrm{Ph} . \mathrm{D}$. degrees in electrical engineering from the Amirkabir University of Technology (Tehran Polytechnique), Tehran, Iran, in 2003 and 2008, respectively.

In 2007, he was with École Polytechnique Fédérale de Lausanne (EPFL), Lausanne, Switzerland, as a Visiting Scientist and later as a Research Assistant. From 2010 to 2015, he was an Assistant Professor with Shahid Beheshti University, Tehran, Iran, where he was as an Associate Professor, from 2015 to 2016. He was an Invited Professor with the EPFL, in 2014. In 2016, he joined the Department of Electrical Engineering, Polytechnique de Montréal, Montréal, QC, Canada, as an Assistant Professor. His current research interests include power system modeling and simulation, smart grids, and electromagnetic compatibility.

Dr. Sheshyekani is currently an Associate Editor of the IEEE TRANSACTIONS ON ELECTROMAGNETIC COMPATIBILITY.

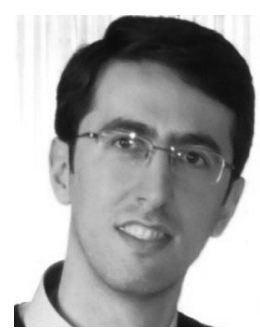

Hamidreza Karami received the B.S. degree in electrical engineering from Bu-Ali Sina University, Hamedan, Iran, in 2004, and the M.S. and Ph.D. degrees in telecommunications from Amirkabir University of Technology, Tehran, Iran, in 2008 and 2013, respectively.

He was with École Polytechnique, Fédérale de Lausanne (EPFL), Lausanne, Switzerland, in June 2013 as a Visiting Scientist. He is currently an Assistant Professor of electrical engineering with Bu-Ali Sina University, Hamedan, Iran. His research interests include electromagnetic compatibility, computational methods in electromagnetics, and microwave nondestructive testing techniques.

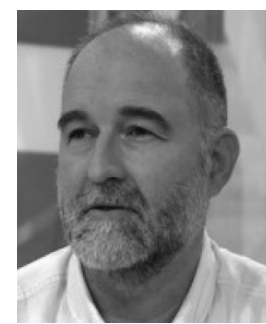

Dragan Poljak (SM'13) was born on October 10, 1965. He received the B.Sc., M.Sc., and Ph.D. degrees from the University of Split, Split, Croatia in 1990, 1994, and 1996, respectively, all in electrical engineering.

He is a Full Professor with the Department of Electronics, Faculty of electrical engineering, mechanical engineering and naval architecture, University of Split, and he is also an Adjunct Professor with Wessex Institute of Technology, Ashurst, U.K. His research interests include frequency and time domain computational methods in electromagnetics, particularly in the numerical modeling of wire antenna structures, and numerical modeling applied to environmental aspects of electromagnetic fields. He has authored or coauthored nearly 200 journal and conference papers in the area of computational electromagnetics, seven authored books and one edited book, by WIT Press, Southampton-Boston, and one book by Wiley, New Jersey.

Dr. Poljak is a member of the Editorial Board of the journal Engineering Analysis with Boundary Elements, and co-chairman of many WIT International Conferences. He is also an editor of the WIT Press Series Advances in Electrical Engineering and Electromagnetics. He was awarded several prizes for his carrier achievements, such as National Prize for Science in 2004, Croation section of the IEEE annual Award in 2016. In 2011, He became a member of WIT Bord of Directors. From 2011 to 2015, he was the Vice-Dean for research with the Faculty of electrical engineering, mechanical engineering and naval architecture. In June 2013, he became a member of the board of the Croatian Science Foundation. He is currently involved in few COST projects, ITER physics EUROfusion collaboration, and one national center for excellence in research for technical sciences. He is a Co-Chair of Working Group 2 of the IEEE/International Committee on Electromagnetic Safety (ICES) Technical Committee 95 SC6 EMF Dosimetry Modeling. 


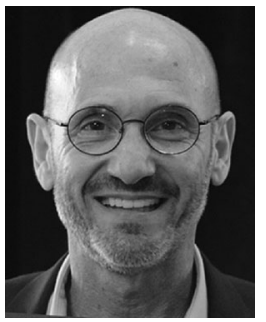

Marcos Rubinstein (M'84-SM'11-F'14) received the Master's and Ph.D. degrees in electrical engineering from the University of Florida, Gainesville, FL, USA, in 1986 and 1991, respectively.

In 1992, he joined the Swiss Federal Institute of Technology, Lausanne, Switzerland, where he was involved in the fields of electromagnetic compatibility and lightning. In 1995, he was with Swisscom, where he worked in numerical electromagnetics and Electromagnetic Compatibility. In 2001, he joined the HES-SO, University of Applied Sciences and Arts, Western Switzerland, Yverdon-les-Bains, Switzerland, where he is currently a Full Professor, head of the advanced Communication Technologies Group and a member of the IICT Institute Team. He is the author or coauthor of more than 200 scientific publications in reviewed journals and international conferences. He is also the coauthor of seven book chapters. He is the Chairman of the International Project on Electromagnetic Radiation from Lightning to Tall structures, was an Editor-in-Chief of the Open Atmospheric Science Journal, and currently an Associate Editor of the IEEE TRANSACTIONS ON ELECTROMAGNETIC COMPATIBILITY. He was recipient of the best Master's Thesis award from the University of Florida. He was recipient the IEEE achievement award and he is a co-recipient of the NASA's Recognition for Innovative Technological Work award. He is a Fellow of the SUMMA Foundation, a member of the Swiss Academy of Sciences, and of the International Union of Radio Science.

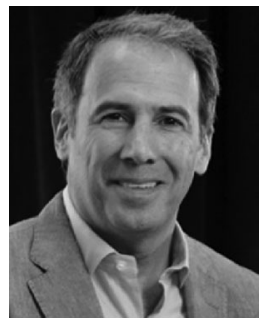

Farhad Rachidi (M'93-SM'02-F'10) received the M.S. degree in electrical engineering and the Ph.D. degree in electrical engineering from the Swiss Federal Institute of Technology, Lausanne, Switzerland, in 1986 and 1991, respectively.

He was with the Power Systems Laboratory, Swiss Federal Institute of Technology, until 1996. In 1997, he joined the Lightning Research Laboratory, University of Toronto, Toronto, ON, Canada. From 1998 to 1999, he was with Montena EMC, Rossens, Switzerland. He is currently a Titular Professor and the Head of the EMC Laboratory with the Swiss Federal Institute of Technology, Lausanne, Switzerland. He has authored or coauthored more than 170 scientific papers published in peer-reviewed journals and more than 350 papers presented at international conferences.

Dr. Rachidi is currently a member of the Advisory Board of the IEEE TRANSACTIONS ON ELECTROMAGNETIC COMPATIBILITY and the President of the Swiss National Committee of the International Union of Radio Science. He was the recipient of numerous awards including the 2005 IEEE TRANSACTIONS ON ELECTROMAGNETiC COMPATIBILITY Technical Achievement Award, the 2005 CIGRE Technical Committee Award, the 2006 Blondel Medal from the French Association of Electrical Engineering, Electronics, Information Technology and Communication (SEE), the 2016 Berger Award from the International Conference on Lightning Protection, the 2016 Best Paper Award of the IEEE TRANSACTIONS ON ELECTROMAGNETIC COMPATIBILITY, and the 2017 Motohisa Kanda Award for the most cited paper of the IEEE TRANSACTIONS ON ELECTROMAGNETIC COMPATIBILITY. In 2014, he was conferred the title of Honorary Professor of the Xi' an Jiaotong University in China. He was the Vice-Chair of the European COST Action on the Physics of Lightning Flash and its Effects from 2005 to 2009, the Chairman of the 2008 European Electromagnetics International Symposium, the President of the International Conference on Lightning Protection from 2008 to 2014, the Editor-in-Chief of the Open Atmospheric Science Journal (2010-2012) and the Editor-in-Chief of the IEEE TRANSACTIONS ON ELECTROMAGNETIC COMPATIBILITY from 2013 to 2015. He is a Fellow of the SUMMA Foundation, and a member of the Swiss Academy of Sciences 